\title{
Methylmercury Exposure and Health Effects
}

\author{
Young-Seoub Hong', Yu-Mi Kim', Kyung-Eun Lee ${ }^{2}$ \\ ${ }^{1}$ Department of Preventive Medicine, Dong-A University College of Medicine, Busan; ${ }^{2}$ Department of Clinical Laboratory Science, Catholic University \\ of Pusan College of Health Science, Busan, Korea
}

Methylmercury is a hazardous substance that is of interest with regard to environmental health, as inorganic mercury circulating in the general environment is dissolved into freshwater and seawater, condensed through the food chain, ingested by humans, and consequently affects human health. Recently, there has been much interest and discussion regarding the toxicity of methylmercury, the correlation with fish and shellfish intake, and methods of long-term management of the human health effects of methylmercury. What effects chronic exposure to a low concentration of methylmercury has on human health remains controversial. Although the possibility of methylmercury poisoning the heart and blood vessel system, the reproductive system, and the immune system is continuously raised and discussed, and the carcinogenicity of methylmercury is also under discussion, a clear conclusion regarding the human health effects according to exposure level has not yet been drawn. The Joint FAO/WHO Expert Committee on Food Additives proposed to prepare additional fish and shellfish intake recommendations for consumers based on the quantified evaluation of the hazardousness of methylmercury contained in fish and shellfish, methylmercury management in the Korea has not yet caught up with this international trend. Currently, the methylmercury exposure level of Koreans is known to be very high. The starting point of methylmercury exposure management is inorganic mercury in the general environment, but food intake through methylation is the main exposure source. Along with efforts to reduce mercury in the general environment, food intake management should be undertaken to reduce the human exposure to methylmercury in Korea.

Key words: Methylmercury, Health effect, Toxicity, Human exposure, Epidemiology

\section{INTRODUCTION}

Methylmercury, which is known to be the most poisonous among the mercury compounds is created when inorganic mercury circulating in the general environment is dissolved into freshwater and seawater. It is known to become condensed

Received: September 21, 2012 Accepted: October 17, 2012

Corresponding author: Kyung-Eun Lee, PhD

57 Oryundae-ro, Geumjeong-gu, Busan 609-757, Korea

Tel: +82-51-510-0562, Fax: +82-51-510-0568

E-mail:kelee@cup.ac.kr

This is an Open Access article distributed under the terms of the Creative Commons Attribution Non-Commercial License (http://creativecommons.org/licenses/by$\mathrm{nc} / 3.0 /$ ) which permits unrestricted non-commercial use, distribution, and reproduction in any medium, provided the original work is properly cited. through the ecological food chain and ingested into humans [1]. Accordingly, methylmercury can be ingested through food intake by people whose occupations are not directly related to mercury exposure, and this can affect human health. Therefore, methylmercury is a hazardous material that deserves the attention of environmental health experts. In air, most mercury exists in the form of inorganic mercury, while it is organic mercury that occupies most of the mercury content in human bodies. $80 \%$ to $90 \%$ of organic mercury in a human body is from fish and shellfish intake, and $75 \%$ to $90 \%$ of organic mercury existing in fish and shellfish is methylmercury. It was reported that $75 \%$ of blood mercury resulted from fish and shellfish intake for more than 30 days [2]. In recent years, extensive studies on the dose-response assessment of methylmercury have been performed, and the concentration of meth- 
ylmercury which is considered safe for human exposure is decreasing as new data are gathered.

Methylmercury is highly poisionous and the toxicity varies according to its form, inflow path, exposure amount, and individual susceptibility. When a pregnant woman is exposed to methylmercury, it may increase the risk of silent birth and the birth of babies with deformities or severe nervous system diseases, even when the mother does not show any symptoms of poisoning $[3,4]$. Accordingly, most developed countries including the US, Canada, and Japan, set and manage recommendation standards for fish and shellfish intake as a part of the protection of vulnerable classes such as pregnant women and infants from methylmercury. In Korea, however, special recommendations for fish and shellfish intake do not exist, with the exception of freshwater fish, although there is a standard allowance for the mercury concentration in fish and shellfish. Furthermore, sufficient data on health disorders occurring in the normal population because of chronic exposure to low concentrations of methylmercury and various effects of poisoning on susceptible classes such as pregnant women and fetuses have not been gathered.

Recently, there has been a great deal of interest in and discussion about the toxicity of methylmercury, its correlation with fish and shellfish intake, and how to manage its effects on human health. In this study, we examined the characteristics, toxicity, and exposure levels of methylmercury, along with examining research trends and proposing a management plan.

\section{OVERVIEW OF THE HEALTH RISKS OF METHYLMERCURY}

\section{Characteristics of Methylmercury}

Mercury is classified as metal mercury, inorganic mercury, and organic mercury. The compounds composed of the combination of hydrogen and carbon are called organic mercury compounds. Organic mercury compounds are classified as allylmercury and alkylmercury compounds. Phenylacetate mercury (an agricultural chemical) and mercurochrome (an antiseptic) are allylmercury compounds and methylmercury and ethylmercury are alkyl mercury compounds [5]. Monomethylmercury and dimethylmercury, which are frequently found in ecological systems, may cause severe contamination to marine ecology. Minamata disease in Japan, which resulted from the intake of mercury-contaminated fish and shellfish, is a famous example [6].
People can be exposed to mercury through air, food, drink, and amalgam-treated teeth. From mercury flowing into the human body, methylmercury is known to have the strongest toxicity to humans, showing a high rate of human residues, such as $95 \%$ in one study [6]. The concentration of total mercury in the air is known to be $<10 \mathrm{ng} / \mathrm{m}^{3}, 22 \%$ of which is monomethylmercury and dimethylmercury. However, the average amount of methylmercury that people take in from the air is $<0.04 \mu \mathrm{g} / \mathrm{d}$, so it can be said that air is not a major exposure source of methylmercury. On the other hand, mercury that has flowed into seas, rivers, and and stream forms ligand combinations with various organic materials and exists in stabilized forms. Methylmercury is not created until inorganic mercury is methylated by microorganisms. Once produced, this methylmercury disperses to pelagic organisms very quickly and is then condensed in the pelagic organisms. It is known that methylmercury accumulates in humans who ingest these pelagic organisms [6]. The concentration of total mercury in most foods other than fish and shellfish is very low, at $<0.01$ $\mu \mathrm{g} / \mathrm{g}$, and most mercury exists in the form of inorganic mercury. However, seafood, such as fish and shellish, contains much higher quantities of mercury and $90 \%$ of mercury exists in the form of methylmercury. Although the concentration of methylmercury in most fishes is reported to be as low as $<0.4 \mu \mathrm{g} / \mathrm{g}$, predatory fishes such as sword fish and shark are reported to contain one to two digits $\mu \mathrm{g} / \mathrm{g}$ of mercury $[6,7]$. As such, predators that are larger, live longer, and are located high on the food chain have higher quantities of mercury $[1,6,7]$.

Inorganic mercury discharged from various contaminants flows into seas, rivers, and streams, is converted to methylmercury by bacteria and plankton in water, is accumulated in pelagic organisms including fish and shellfish, and flows into humans through fish and shellfish intake by humans $[1,6]$. When methylmercury flows into the human body, it produces disulfides with a high chemical affinity to sulfhydryl groups from proteins. Disulfides make protein structures and enzyme functions nonspecific and cause poisoning [8,9]. Because of this, people who live in mercury-contaminated areas suffer from acute or chronic mercury poisoning without occupational exposure.

\section{Toxicokinetics}

\section{Absorption}

While the absorption rate of inorganic mercury is not more than $2 \%$ to $38 \%$, organic mercury is absorbed nearly complete- 
ly and flows into the blood [10]. When people ingest methylmercury-contaminated food, methylmercury is separated by gastric acid. It combines with cysteine among the amino acids in the duodenum and almost $100 \%$ of the mercury is absorbed. Afterwards, it combines with the hemoglobin of red blood cells through the portal vein, is accumulated in the central nervous system, and causes disorders of the neurons [11]. In an animal experiment, up to $95 \%$ of methylmercury was absorbed by the lungs. As it is easily dissolved in fat and absorbed in the digestive tract quickly, methylmercury showed 17 to 35 times faster absorption than inorganic mercury. The maximum blood methylmercury concentration was found 6 hours after food exposure, and $95 \%$ of intake was absorbed [12].

\section{Distribution}

Methylmercury has high affinity with the sulfhydryl protein group. When it is ingested into the human body, it combines with glutathione to make methylmercury-glutathione compound and is distributed to various tissues and organs through the blood vessels $[9,13]$. It easily crosses the blood-brain barrier and placenta and is accumulated in the brain of fetuses more than in mothers [5]. The concentration of methylmercury in organisms is relatively stable proportional to the blood concentration and $90 \%$ of methylmercury is distributed in red blood cells. Accordingly, if we measure the blood methylmercury concentration, we can infer the concentration in the organs. When methylmercury was injected into pregnant mice, a 1.7 to 4.8 times higher mercury concentration was detected in the brain of the fetus than in that of the mother [12]. As methylmercury is fat-friendly, it crosses the cell membrane very easily. Although the placenta cross rate of methylmercury is 10 times higher than other mercury compounds, the transition from blood methylmercury to breast milk was lower than that from inorganic mercury [12]. It is known that when people are exposed to methylmercury, blood mercury moves to the follicle in the hair growth stage and is accumulated there. It has also been shown that the mercury concentration in hair is proportional to the blood concentration [12].

\section{Metabolism}

It is known that methylmercury is converted to bivalence inorganic mercury and undergoes oxidation and reduction [10]. Methylmercury releases oxygen radicals at decomposition and the released oxygen radical causes severe damage to cells by activating the chain of lipid peroxidation of the cell membrane
[13]. It has been proven that methylmercury has high fat solubility, is toxic to the central nervous system which has a high fat content [13].

\section{Excretion}

The main excretion paths of methylmercury are known to be the bile and feces. Methylmercury is excreted in the bile, but a part of it is reabsorbed through enterohepatic cycling and flows to the liver $[6,10]$. Most methylmercury is dissolved by demethylation and excreted to the feces in ion form. In case of applicant subject who was exposed to a methylmercury application once, excretion through the feces occupied $90 \%$ of total mercury excretion [10]. As methylmercury excretion via the urine is very slight, methylmercury concentration is not detected accurately in the urine because of the existence of inorganic mercury. Therefore, the concentration of mercury in the urine cannot be a good index for measuring the body's accumulation of methylmercury or its concentration in major organs [13]. The half-life period of methylmercury, that is, the time in which the content of methylmercury in the body is reduced to half through excretion, is 70 days on average. Additionally, organic mercury can be excreted through breast milk and the half-life period of methylmercury in breast feeding women is much shorter than in other women [6].

\section{Health Effects of Methylmercury Neurotoxicity}

The neurotoxicity of methylmercury is well known through worldwide intoxication incidents and studies regarding low concentration exposure. Methylmercury is a strong toxin that influences enzymes, cell membrane function, and neuron delivery materials; causes oxidative stress, lipid peroxidation, and mitochondria dysfunction; and distracts synapse transmission, microtubule composition, amino acid transport, and cellular migration in growing brains [14]. It is reported that there are motor disturbances such as ataxia and trembling, and dysesthesia such as impaired vision [5].

It was first discovered that methymercury had fatal effects on the brain development of fetuses through mercury poisoning incidents in Minamata, Japan in the 1950s [6]. While there were only trivial or no symptoms of intoxication in mothers, infants showed central nervous disturbances such as paralysis and intelligence disorders. In the hair of Minamata residents, 280 to 760 ppm of mercury was detected [11]. Considering that the hair mercury concentration of normal people is 2 ppm, 
$5 \mathrm{mg} / 70 \mathrm{~kg}$ is defined as mercury poisoning, and 150 to 300 $\mathrm{mg} / 70 \mathrm{~kg}$ is a lethal dose; it is a very high concentration [11]. All the children with Minamata disease suffered from mental retardation, cerebellar ataxia, physical growth disorder, dysarthria, and limb deformities. Most of them showed hyperkinesis, hypersalivation, seizures, and strabismus [6,12].

In Iraq in the early 1970s, there was an incident in which 6350 people were poisoned by mercury by eating bread made of grain containing chemicals including mercury. Of them, 409 died [6]. As it was caused by an acute exposure to a higher concentration of mercury than in the Minamata area, the poisoned children showed dysesthesia, paralysis, cerebral palsy and mental disorder symptoms. Those who were measured as having $25 \mathrm{mg}$ of methylmercury showed dysesthesia at first; $50 \mathrm{mg}$, dysbasia; $90 \mathrm{mg}$ balbuties; $180 \mathrm{mg}$, hearing disorders; and those who were measured at $200 \mathrm{mg}$ died. On the other hand, it is estimated that when methylmercury is ingested constantly at a rate of $50 \mu \mathrm{g}$ per day, the risk of dysesthesia will increase by $0.3 \%$, and at $200 \mu \mathrm{g}$ per day, the risk will increase by $8 \%$ [6].

Although children in New Zealand and the Faroe Islands were exposed to remarkably lower concentrations of methylmercury than in the Japan and Iraq poisoning incidents, they showed disorders in intelligence quotient, language, visualspatial skills, gross motor skills, memory, and concentration [15-18]. However, a recent study regarding the effects of methylmercury exposure because of food intake after birth on the central nervous system did not prove a clear cause-effect relationship although several correlations in neurological examination were found [19]. In the same study, it is reported that recent methylmercury exposure had effects on the ability to perform addition, and a signal and number matching test, but it did not have effects on simple response time or selection response time tests [19].

In Korea, blood mercury concentration was measured in 1778 six- to ten-year-old children and no special correlation with attention deficit hyperactivity disorder (ADHD) prevalence was found [20]. On the other hand, in China and Hong Kong, it was reported that ADHD prevalence increased with increasing blood mercury concentration [21], and it was also reported that the hair mercury concentration of Spanish children was correlated with their visual-spatial skills [22]. It is thought that extensive study on complicated exposure including various concentrations and various metals should be performed in the future.

\section{Reproductive effects}

The reproductive toxicity of methylmercury has been confirmed. In several studies, the correlation between chromosomal anomaly and sister-chromatid exchange according to methylmercury exposure was identified [23]. The reproductive toxicology shown in experimental animals exposed to high concentration methylmercury for a short period included reduced number of sperms, testicular atrophy, reduced size of infants in one birth, reduced survival rate of fetuses, and fetus deformity [24]. When injecting 0.4 to $0.8 \mathrm{mg} / \mathrm{kg}$ methylmercury dicyandiamide into the stomach cavity of mice at the seventh, ninth, and twelfth day of pregnancy, growing fetuses showed the greatest sensitivity to methylmercury toxicity [25]. To distinguish the influence of the exposure before and after birth on two variables, survival and weight gain, surrogate nurturing and cross nurturing were performed right after the birth. The death rate because of exposure before birth was 2 times higher than that because of exposure after birth, and the influence was greatest at the end of organogenesis. The effects on mother animals were not conspicuous, but it was found that methylmercury exposure in the womb could be much more dangerous to children than the exposure after birth through breast milk [25]. However, further studies regarding the reproductive toxicology of humans exposed to low concentration methylmercury should be performed.

\section{Immunotoxicity}

The immunotoxicity of methylmercury on humans have not been confirmed. According to animal experiments, a mouse which had been fed feed containing $3.2 \mathrm{mg} / \mathrm{kg}$ of methylmercury did not show any changes in body weight or weight of the kidney, liver and spleen but the weight of the thymus and the number of thymocytes were reduced by $22 \%$ and $50 \%$, respectively. While the lymph cell proliferation response against $\mathrm{T}$ cell and $\mathrm{B}$ cell mitogen increased in the thymus and spleen, NK cell activation was reduced by $44 \%$ in the spleen, and by $75 \%$ in the blood [12]. Additionally, methylmercury caused the malfunction of mastocytes in rodents [26].

According to a report of the National Research Council (NRC) [23], people exposed to high concentration methylmercury such as those who live near the Amazon River and eat fish as a staple food and those who work in gold mines, have been observed to have an increased frequency of antinuclear autoantibodies, changes in serum cytokine levels, and an increased risk of malaria infection $[27,28]$. 
Recently, it was reported that atopic dermatitis increased when the mercury concentration was high [29], but there have not been study results that could prove the effects of methylmercury on human immunity in Korea. However, considering the result of animal experiments, the possibility of immunotoxicity of methylmercury on human bodies cannot be ignored, so further studies should be performed.

\section{Carcinogenicity}

No epidemiological study on human beings has clearly shown a relationship between methylmercury exposure and cancer occurrence in an. Although one study has raised the possibility of leukemia because of mercury exposure, it could not clearly show the relationship between them because of factors such as limited population. It was reported that factory workers in a chloralkali plant in Sweden had two times higher risks of obtaining lung cancer, and the risk of brain cancer and kidney cancer were higher, but statistical significance was not observed [12]. In animal experiments, in mice fed with $10 \mathrm{mg} / \mathrm{kg}$ of methylmercury, chronic kidney failure, adenoma, and carcinoma were observed. In other words, it was reported that rodents exposed to methylmercury chloride showed a higher incidence of kidney cancer [12]. The International Agency for Research on Cancer judged that there is sufficient evidence of the carcinogenicity of methylmercury chloride on experimental animals and designated methylmercury as a Group 2B material (possibly carcinogenic to humans) [30], while the US Environmental Protection Agency designated it as a Group C material (possible human carcinogen) because it believed that evidence of the carcinogenicity of methylmercury in humans was insufficient and the rationale of the carcinogenicity in experimental animals was restricted [24].

\section{Cardiovascular effects}

Up to now, the relationship between methylmercury and cardiovascular toxicity has not been clearly identified through limited studies. However, the probability of the correlation between methylmercury exposure and cardiovascular toxicity has been raised consistently through some studies. It is known that mercury promotes the creation of free radicals, and that methylmercury disturbs the anti-oxidation effects of glutathione and catalase as it has a high affinity with the thiol group, causes lipid peroxidation, promotes platelet aggregation and blood coagulation, causes sclerosis of the arteries, and raises the blood pressure [31,32]. Consequently, the risk of myocar- dial infarction is increased, and the danger of death is increased because of coronary heart disease and cardiovascular diseases [32]. Methylmercury shows fatal toxicity to the brains of children, whose brains are still developing, on the other hand, exposure shows a higher toxicity to adults than to children with regard to the incidence of cardiovascular diseases.

In Denmark, a case was reported in which children exposed to mercury showed increased blood pressure, both systolic and diastolic, and a reduced heart rate variability when they became 7 years old [33], and reduced sympathetic and parasympathetic nerve functions of the heart as heart rate variability values in both low frequency areas and high frequency areas decreased when they became 14 years old [34]. In a study researching the effects of low mercury exposure on the cardiovascular system in Finland, when male adults were traced for 14 years, it was found that death from coronary heart disease and incidence of acute myocardial infarction became twice as high as hair mercury concentration increased by $2 \mu \mathrm{g} / \mathrm{g}$ after correction for selenium, docosahexaenoic acid, docosapentaenoic acid and vitamin $E$ ingestion and other cardiovascular disease incurring risk factors [31,32]. Rissanen et al. [35] reported that fish oil-derived fatty acids reduced the risk of acute coronary events. But Virtanen et al. [32] reported that increased mercury exposure was associated with increased risk of acute coronary events and cardiovascular mortality. It is interpreted that mercury weakened the positive effects of fish.

The NRC concluded that mercury exposure would have effects on cardiovascular diseases, reporting that methylmercury's toxic effects include increased blood pressure as it was accumulated in heart, and noting that in mercury poisoning incidents, abnormal heartbeats, abnormal electrocardiogram, and myocarditis were reported [23]. In Korea, it was reported that elementary school students with higher urine mercury concentration showed a significantly higher blood cholesterol level, and proposing the possibility that mercury might affect the cardiovascular system, as the group with higher blood pressure in the relaxation period showed a relatively higher urine mercury concentration than the group with normal blood pressure [36]. Another study reported that hair mercury concentration had significant positive correlation with age, blood pressure in the contraction and relaxation period, total cholesterol, neutral fat, low density lipid protein cholesterol, and body mass index, while it had a significant negative correlation with standard deviation of the NN intervals, total power, low frequency, and high frequency (HF) values in heart rate, 
high density lipid protein cholesterol, and heart rate variability tests [37]. Additionally, it reported that even after the correction of cardiovascular disease risk factors such as age and gender, when the hair mercury concentration increased by $1 \mathrm{ppm}$, the heart rate decreased by 2.6 beats/min, the Ln (HF) decreased by $0.131 \mathrm{~ms}$, and the HF norm decreased by 2.550 [37]. This can be interpreted as a confirmation of the effects of mercury exposure on the parasympathetic nerve system of the heart. However, from some other perspectives, the heart protection effects of omega- 3 and selenium contained in fish are proposed. Therefore, it is judged that the positive effects of such content in fish should be considered together, when the cardiovascular toxicity of methylmercury is analyzed.

\section{Human Epidemiological Studies of Methylmer- cury}

Minamata disease and the Iraq grain contamination incident are the most famous environmental contamination incidents by food contaminated by methylmercury. They showed the extreme effects of acute and extensive exposure to methylmercury on humans. Three epidemiological studies to evaluate the effects of low concentration or medium concentration of methylmercury exposure on human bodies, the studies in the Faroe Islands, Seychelles, and New Zealand, are long-term observation studies regarding the health effects by fish intake under conditions without special contaminants.

In New Zealand in 1978, the first cohort study on pregnant women was performed. When analyzing the hair mercury concentration of 1000 pregnant women, 73 pregnant women were found to have a hair mercury concentration of more than $6 \mu \mathrm{g} / \mathrm{g}$. In the follow up observation, children whose mothers' hair mercury concentration was 13 to $15 \mu \mathrm{g} / \mathrm{g}$ during pregnancy showed low intelligence. Although the contribution rate of methylmercury was low, there were significant effects according to the children's racial differences $[16,38,39]$. In the Faroe Island study, the pilot whale that residents frequently ate contained methylmercury at the level of $2 \mathrm{mg} / \mathrm{kg}$. When tracing the birth cohort group in this area for 7 years, children whose mothers were exposed to mercury much showed disorders in concentration, memory, and speech capabilities [40]. In the preliminary study for the Seychelles study, the correlation between methylmercury exposure in prenatal life and neurotoxic anomalies was observed, but these were not interpreted as clear effects of mercury exposure. In the present study, the effects of methylmercury exposure on neurological, cognitive, and behavioral disorders were not observed [17,19]. On the other hand, in the Faroe Islands and New Zealand studies, the correlation between neuropsychological effects and exposure dose was observed. In particular, the Faroe Island study evaluated the neurotoxicity of methylmercury exposure during the period of growth, and the New Zealand study provided information on how to establish a reduction plan to prevent children from methylmercury exposure from the perspective of public health. However, in the Faroe Islands study, simultaneous exposure to polychlorinated biphenyls and other materials as well as to mercury made the result controversial [15]. Furthermore, because the cultural differences between areas were not taken into account, for example, the intake of pilot whale on the Faroe Islands is very high although their fish intake is low, while residents in Seychelles eat fish nearly every day, reevaluation was performed in $2002[17,19]$.

The study results in the Faroe Islands, Seychelles, and New Zealand were used in reevaluation of the hazardousness of mercury [26]. In the Seychelles study, the hair mercury concentration of mothers corresponding to no-observed-effectlevel in the nervous tissues was identified and in the Faroe Islands and New Zealand studies, the results were used to fix a benchmark dose limit (BMDL) through mathematical analysis of the relationship between doses and symptoms [26]. However, in the New Zealand study, one of the 237 mothers showed $86 \mathrm{mg} / \mathrm{kg}$ of hair mercury concentration, which is nearly four times higher than the second highest mother. Accordingly, if this case is excluded, the BMDL is 7.4 to $10 \mathrm{mg} / \mathrm{kg}$, but if this case is included, the BMDL becomes 17 to $24 \mathrm{mg} / \mathrm{kg}$. As the inclusion of the case influences the BMDL too much, in the evaluation of data in the New Zealand study, the case was excluded. The study results in the Faroe Islands and Seychelles showed that the hair mercury concentration of the mother which did not cause any side effects in children was $14 \mathrm{mg} / \mathrm{kg}$; the average of two experiments was used. In many studies, the hair and blood mercury concentration ratio was reported to be 140:370, and the Joint FAO/WHO Expert Committee on Food Additives (JECFA) calculated the blood mercury concentration of $56 \mu \mathrm{g} / \mathrm{L}$ using the total average ratio (250) from the hair mercury concentration. Additionally, to convert the blood mercury concentration to daily intake, JECFA used a one-compartment model. It applied 0.014 day $^{-1}$ as the internal removal rate, $5.85 \mathrm{~L}$ as the blood volume, 0.95 as the internal absorption rate, 0.05 as the blood absorption rate, and $65 \mathrm{~kg}$ as the average weight. Daily ingestion calculated as such was $1.5 \mu \mathrm{g} /$ 
$\mathrm{kg}$ body weight per day. This value represents the maximum blood mercury concentration of the mother when there are no side effects at all. By applying an uncertainty factor of 6.4 against $1.5 \mu \mathrm{g} / \mathrm{kg}$ body weight per day, which is the calculated daily ingestion, it the provisional tolerable weekly intake (PTWI) was reevaluated to be $1.6 \mu \mathrm{g} / \mathrm{kg}$ body weight per week [41,42].

In Korea, most studies on mercury in the human body have addressed blood mercury concentration, and epidemiological studies analyzing blood methylmercury concentration are very limited. The reasons are because blood mercury concentration has a significant correlation with methymercury concentration, and because it is very difficult to measure methylmercury in the blood compared to total mercury in the blood. However, the toxic effects of mercury differ according to its properties and the ratio of methylmercury to total mercury varies according to the population and occupational exposure. Therefore, it is necessary to measure methylmercury in the blood directly and perform epidemiological investigations utilizing the measured value.

In Korea, an epidemiological study evaluating blood methylmercury was first performed on pregnant women. It is known that pregnant women are vulnerable to methylmercury exposure and a high blood mercury concentration in pregnant women may cause irreversible damage to children, including developmental disorders, by influencing the cerebral nerves of fetuses, although a small amount and low concentration of mercury does not cause any symptoms in mothers. Furthermore, that the mercury concentration of cord blood is higher than the blood mercury concentration of the pregnant woman [4], and that methylmercury concentration of cord blood is approximately two times higher than the blood methylmercury concentration of the mother is a very serious problem [43]. Lee et al. [44] observed that the average mercury concentration in cord blood was 1.72 times higher, at 5.43 ppb, than the average mercury concentration of maternal blood of 3.16 ppb in a study on 59 pregnant women. Additionally, the cord blood high risk group exceeding $5 \mu \mathrm{g} / \mathrm{L}$ of human biomonitoring I values (HBM-I) [45] was high, at $49.2 \%$. Methylmercury was $85 \%$ of total mercury in maternal blood and $90.4 \%$ in cord blood. The correlation coefficient of total mercury and methylmercury was observed to be 0.937 and 0.978 in maternal blood and cord blood, respectively. The difference in the mercury concentration between the mother's blood and cord blood is because as the methylmercury moves through the human body by combining with hemoglobin and glutathione, fetuses have higher hemoglobin values and because the half-life of methylmercury is long, it accumulates in the human body for a long period of time. Therefore, as the total mercury concentration of the mother increases, the blood mercury concentration of the newborn infant increases, which means an increasing possibility of neurological and developmental disorders because of mercury. You et al. [46] analyzed the blood concentration of total mercury and methylmercury in 400 residents in 30 areas of Busan, Ulsan and Gyeongsangnam-do province in Korea. They reported that the concentration of methylmercury was $4.05 \mu \mathrm{g} / \mathrm{L}$, which was $78.53 \%$ of the total mercury concentration $(5.27 \mu \mathrm{g} / \mathrm{L})$, that males showed a higher methylmercury concentration than females, that the blood methylmercury concentration increased significantly as the total mercury concentration increased, and that the methylmercury concentration had a significant correlation with fish intake. In sum, methylmercury management is the most important strategy for reducing the blood mercury concentration, as it occupies the largest proportion of total mercury in blood.

In Korea, blood methylmercury has not been directly analyzed. Most of the studies have analyzed total mercury in the blood. They have been performed as nationwide exposure status surveys of the general public, high risk area surveys, and high risk subject surveys from the perspective of environmental health. Table 1 shows the results of a meta-analysis of blood mercury concentration of a survey of the general public in Korea from 2005 to 2010. The average blood mercury concentration in Korea was $3.80 \mu \mathrm{g} / \mathrm{L}$, which is 4 to 7 times higher than in the USA $(0.98 \mu \mathrm{g} / \mathrm{L})$ and Germany $(0.58 \mu \mathrm{g} / \mathrm{L})$. It should be taken seriously that the high risk group, that is, those exceeding the standard of HBM-I ( $5 \mu \mathrm{g} / \mathrm{L})$, make up approximately $40 \%$ of the total. Additionally, as there is no conspicuous reduction trend in the blood mercury concentration, the Ministry of Environment has prepared Comprehensive Mercury Countermeasures and has initiated an effort to reduce the high risk group to $15 \%$ by 2015 . In addition, the Mothers and Children's Environmental Health Study on high risk groups such as pregnant women and infants [47] and the Children's Health and Environmental Research study on children and youths are being performed in Korea using a cohort research design. It is expected that they will be able to evaluate the health effects of low concentration methylmercury chronic exposure. 
Table 1. Summary measures of blood mercury concentration in Koreans

\begin{tabular}{|c|c|c|c|c|c|c|}
\hline Year & Survey & Sex & $\mathbf{n}$ & GM & $\begin{array}{c}95 \% \\
\text { LC }\end{array}$ & $\begin{array}{l}95 \% \\
\text { UC }\end{array}$ \\
\hline \multirow[t]{3}{*}{2007} & \multirow{3}{*}{$\begin{array}{l}\text { The second Korean National } \\
\text { Human Exposure and Bio- } \\
\text { monitoring Examination }\end{array}$} & Total & 2276 & 3.8 & 3.66 & 3.93 \\
\hline & & $\mathrm{M}$ & 797 & 4.94 & 4.66 & 5.24 \\
\hline & & $\mathrm{F}$ & 1531 & 3.27 & 3.13 & 3.42 \\
\hline \multirow[t]{3}{*}{2008} & \multirow{3}{*}{$\begin{array}{l}\text { The third Korean National } \\
\text { Human Exposure and Bio- } \\
\text { monitoring Examination }\end{array}$} & Total & 5129 & 3 & 2.93 & 3.07 \\
\hline & & $\mathrm{M}$ & 1580 & 3.87 & 3.71 & 4.04 \\
\hline & & $\mathrm{F}$ & 3549 & 2.68 & 2.6 & 2.75 \\
\hline 2009 & $\begin{array}{l}\text { Korea National Environmen- } \\
\text { tal Health Survey }\end{array}$ & Total & 2102 & 3.93 & 3.85 & 4.02 \\
\hline 2010 & $\begin{array}{l}\text { Korea National Environmen- } \\
\text { tal Health Survey }\end{array}$ & Total & 2114 & 2.88 & 2.8 & 2.97 \\
\hline \multirow[t]{3}{*}{2005} & \multirow{3}{*}{$\begin{array}{l}\text { Korea National Health and } \\
\text { Nutritional Examination }\end{array}$} & Total & 2000 & 4.34 & 4.21 & 4.48 \\
\hline & & $\mathrm{M}$ & 1001 & 5.01 & 4.8 & 5.22 \\
\hline & & $\mathrm{F}$ & 999 & 3.76 & 3.6 & 3.93 \\
\hline \multirow[t]{3}{*}{2008} & \multirow{3}{*}{$\begin{array}{c}\text { Korea National Health and } \\
\text { Nutritional Examination }\end{array}$} & Total & 2006 & 4.71 & 4.6 & 4.83 \\
\hline & & $\mathrm{M}$ & 1000 & 5.55 & 5.37 & 5.75 \\
\hline & & $\mathrm{F}$ & 1006 & 4 & 3.88 & 4.13 \\
\hline \multirow[t]{3}{*}{2009} & \multirow{3}{*}{$\begin{array}{c}\text { Korea National Health and } \\
\text { Nutritional Examination }\end{array}$} & Total & 1991 & 4.28 & 4.17 & 4.39 \\
\hline & & $\mathrm{M}$ & 995 & 5.17 & 4.98 & 5.37 \\
\hline & & $\mathrm{F}$ & 996 & 3.54 & 3.43 & 3.66 \\
\hline \multirow{3}{*}{\multicolumn{2}{|c|}{ Pooled summary }} & Total & 17618 & 3.80 & 3.76 & 3.84 \\
\hline & & M & 5373 & 4.95 & 4.86 & 5.04 \\
\hline & & $\mathrm{F}$ & 8081 & 3.35 & 3.30 & 3.40 \\
\hline
\end{tabular}

GM, geometric mean; LC, lower confidence; UC, upper confidence.

\section{CONCLUSION}

Given that methylmercury can have various effects on human health, not only through high concentration acute exposure, but also by low concentration chronic exposure, more active management of mercury is required. The starting point of methylmercury exposure is inorganic mercury in the general environment. However, because food intake through the methylation process is the main exposure path, dietary management countermeasures are needed along with the effort to reduce mercury in the general environment.

As the long-term birth cohort tracing studies on low concentration chronic exposure to mercury in the Faroe Islands, Seychelles, and New Zealand where high fish intake exists without other forms of exposure to contaminants showed, children whose mother had a high mercury exposure were observed to have disorders in concentration, memory, and speech. However, because of the beneficial nutrients of fish and shellfish that accompany exposure to methylmercury's toxicity, fish and shellfish intake recommendations should be developed more precisely through quantified evaluation of methylmercury instead of simply warning against ingesting fish and shellfish.

Major countries have established daily ingestion tolerances for mercury along with fish and shellfish intake recommendations. The US has prepared fish consumption advisories in $\mathbf{4 8}$ states and state governments have made proactive advertisements to their citizens. Japan investigated the mercury concentration of various fishes, prepared national fish intake recommendations to restrict the number of instances of intake and the volume of many species of predatory fish for pregnant women and fertile women, and advertised the recommendations through the mass media. On the other hand, Korea does not have recommended standards on much consumed sea fishes including tuna sashimi, presenting recommendations on freshwater fish only. Therefore, countermeasures are needed.

The CODEX Alimentarius concluded that embryos and fetuses are the most vulnerable to methylmercury exposure based on various study results. Therefore, it claimed that to reduce the methylmercury exposure level, it would be more important to have proactive communication on the hazardousness of mercury for the high risk group, in other words, fertile women or pregnant women, than setting general fish intake guidelines and communicating the hazard to the general public. In Korea, in a study on the total mercury concentration of the mother's blood and the cord blood of mothers registered in the mother cohort study from 2005 to 2010, it was observed that the increased total mercury concentration of cord blood would reduce the weight of a newborn. However, the information was not sufficient to reveal the precise relationship between them. Thus, a further long-term observational study is needed. Considering this, an effort should be made to reduce mercury concentration by preparing locally suitable fish and shellfish intake recommendations and enforcing the advertisement of the hazardousness of mercury to prevent incidents in advance. Thus, to minimize health damage by low concentration methylmercury chronic exposure, a national environmental health policy is needed so that related authorities such as the Ministry of Environment, Korean Food and Drug Administration, Ministry of Health and Welfare, and Ministry of Agriculture, Fisheries and Food can collaborate to prepare countermeasures and enforce them. 


\section{ACKNOWLEDGEMENTS}

This research was supported by a grant (10162KFDA994) from Korea Food and Drug Administration in 2012.

\section{CONFLICT OF INTEREST}

The authors have no conflicts of interest with the material presented in this paper.

\section{REFERENCES}

1. US Environmental Protection Agency. Mercury study report to Congress [cited 2012 Oct 2]. Available from: http://www.epa. gov/hg/report.htm.

2. Mahaffey KR, Clickner RP, Bodurow CC. Blood organic mercury and dietary mercury intake: National Health and Nutrition Examination Survey, 1999 and 2000. Environ Health Perspect 2004;112(5):562-570.

3. Fuyuta M, Fujimoto T, Hirata S. Embryotoxic effects of methylmercuric chloride administered to mice and rats during orangogenesis. Teratology 1978;18(3):353-366.

4. Tsuchiya H, Mitani K, Kodama K, Nakata T. Placental transfer of heavy metals in normal pregnant Japanese women. Arch Environ Health 1984;39(1):11-17.

5. Agency for Toxic Substances and Disease Registry. Toxicological profile for mercury [cited 2012 Oct 2]. Available from: http://www.atsdr.cdc.gov/toxprofiles/tp.asp?id=115\&tid=24.

6. International Program on Chemical Safety. Environmental methylmercury: health criteria 101. Geneva: World Health Organization; 1990 [cited 2012 Oct 2]. Available from: http:// www.inchem.org/documents/ehc/ehc/ehc101.htm.

7. Grandjean P, White RF, Weihe P, Jørgensen PJ. Neurotoxic risk caused by stable and variable exposure to methylmercury from seafood. Ambul Pediatr 2003;3(1):18-23.

8. Hughes WL. A physicochemical rationale for the biological activity of mercury and its compounds. Ann N Y Acad Sci 1957; 65(5):454-460.

9. Kim DS, Kim GB, Park KH, Kang TS, Lee JH, Nam SH, et al. A study on exposure and health effect of mercury (II). Incheon: National Institute of Environmental Research; 2006, p. 1-115 (Korean).

10. Abernethy DR, Destefano AJ, Cecil TL, Zaidi K, Williams RL; USP Metal Impurities Advisory Panel. Metal impurities in food and drugs. Pharm Res 2010;27(5):750-755.
11. Lee C, Cho SD, Chang DS, Shin DH, Oh DH, Whang I, et al. Food safety guidelines for consumer. Safe Food 2006;1(4):31-43 (Korean).

12. World Health Organization. Safety evaluation of certain food additives and contaminants: methylmercury [cited 2012 Oct 2]. Available from: http://whqlibdoc.who.int/publications/2011/9789241660648_eng.pdf.

13. Korea Food and Drug Administration. Hazardous substances-21 series: what is methylmercury in food? Seoul: Korea Food and Drug Administration; 2007, p. 1-68 (Korean).

14. Sager PR, Matheson DW. Mechanisms of neurotoxicity related to selective disruption of microtubules and intermediate filaments. Toxicology 1988;49(2-3):479-492.

15. Grandjean P, Weihe P, White RF, Debes F, Araki S, Yokoyama K, et al. Cognitive deficit in 7-year-old children with prenatal exposure to methylmercury. Neurotoxicol Teratol 1997;19(6): 417-428.

16. Crump KS, Kjellström T, Shipp AM, Silvers A, Stewart A. Influence of prenatal mercury exposure upon scholastic and psychological test performance: benchmark analysis of a New Zealand cohort. Risk Anal 1998;18(6):701-713.

17. Myers GJ, Davidson PW, Cox C, Shamlaye CF, Palumbo D, Cernichiari $\mathrm{E}$, et al. Prenatal methylmercury exposure from ocean fish consumption in the Seychelles child development study. Lancet 2003;361(9370):1686-1692.

18. Debes F, Budtz-Jørgensen E, Weihe P, White RF, Grandjean P. Impact of prenatal methylmercury exposure on neurobehavioral function at age 14 years. Neurotoxicol Teratol 2006;28(3): 363-375.

19. Myers GJ, Thurston SW, Pearson AT, Davidson PW, Cox C, Shamlaye $\mathrm{CF}$, et al. Postnatal exposure to methyl mercury from fish consumption: a review and new data from the Seychelles Child Development Study. Neurotoxicology 2009;30(3):338-349.

20. Ha M, Kwon HJ, Lim MH, Jee YK, Hong YC, Leem JH, et al. Low blood levels of lead and mercury and symptoms of attention deficit hyperactivity in children: a report of the children's health and environment research (CHEER). Neurotoxicology 2009; 30(1):31-36.

21. Cheuk DK, Wong V. Attention-deficit hyperactivity disorder and blood mercury level: a case-control study in Chinese children. Neuropediatrics 2006;37(4):234-240.

22. Torrente M, Colomina MT, Domingo JL. Metal concentrations in hair and cognitive assessment in an adolescent population. Biol Trace Elem Res 2005;104(3):215-221.

23. National Research Council. Toxicological effects of methylmer- 
cury [cited 2012 Oct 2]. Available from: http://www.nap.edu/ openbook.php?record_id=9899\&page $=147 /$.

24. Environmental Protection Agency. Methylmercury (MeHg) (CASRN 22967-92-6); 2009 [cited 2012 Nov 8]. Available from: http://www.epa.gov/iris/subst/0073.htm.

25. Spyker DA, Spyker JM. Response model analysis for cross-fostering studies: prenatal versus postnatal effects on offspring exposed to methylmercury dicyandiamide. Toxicol Appl Pharmacol 1977;40(3):511-527.

26. World Health Organization. Evaluation of certain food additives and contaminants: sixty-first report of the joint FAO/WHO Expert Committee on Food Additives [cited 2012 Oct 2]. Available from: http://whqlibdoc.who.int/trs/WHO_TRS_922.pdf.

27. Crompton P, Ventura AM, de Souza JM, Santos E, Strickland GT, Silbergeld E. Assessment of mercury exposure and malaria in a Brazilian Amazon riverine community. Environ Res 2002;90(2): 69-75.

28. Gardner RM, Nyland JF, Silva IA, Ventura AM, de Souza JM, Silbergeld EK. Mercury exposure, serum antinuclear/antinucleolar antibodies, and serum cytokine levels in mining populations in Amazonian Brazil: a cross-sectional study. Environ Res 2010;110(4):345-354.

29. Park H, Kim K. Association of blood mercury concentrations with atopic dermatitis in adults: a population-based study in Korea. Environ Res 2011;111(4):573-578.

30. Beryllium, cadmium, mercury, and exposures in the glass manufacturing industry. Working Group views and expert opinions. Lyon, 9-16 February 1993. IARC Monogr Eval Carcinog Risks Hum 1993;58:1-415.

31. Salonen JT, Seppänen K, Nyyssönen K, Korpela H, Kauhanen J, Kantola $\mathrm{M}$, et al. Intake of mercury from fish, lipid peroxidation, and the risk of myocardial infarction and coronary, cardiovascular, and any death in eastern Finnish men. Circulation 1995;91(3):645-655.

32. Virtanen JK, Voutilainen S, Rissanen TH, Mursu J, Tuomainen TP, Korhonen MJ, et al. Mercury, fish oils, and risk of acute coronary events and cardiovascular disease, coronary heart disease, and all-cause mortality in men in eastern Finland. Arterioscler Thromb Vasc Biol 2005;25(1):228-233.

33. Sørensen N, Murata K, Budtz-Jørgensen E, Weihe P, Grandjean P. Prenatal methylmercury exposure as a cardiovascular risk factor at seven years of age. Epidemiology 1999;10(4):370-375.

34. Grandjean P, Murata K, Budtz-Jørgensen E, Weihe P. Cardiac autonomic activity in methylmercury neurotoxicity: 14-year follow-up of a Faroese birth cohort. J Pediatr 2004;144(2):169-
176.

35. Rissanen T, Voutilainen S, Nyyssönen K, Lakka TA, Salonen JT. Fish oil-derived fatty acids, docosahexaenoic acid and docosapentaenoic acid, and the risk of acute coronary events: the Kuopio ischaemic heart disease risk factor study. Circulation 2000;102(22):2677-2679.

36. Kim DS, Lee EH, Yu SD, Cha JH, Ahn SC. Heavy metal as risk factor of cardiovascular disease: an analysis of blood lead and urinary mercury. J Prev Med Public Health 2005;38(4):401-407 (Korean).

37. Lim S, Choi MC, Joh KO, Paek D. The health effects of mercury on the cardiac autonomic activity according to the heart rate variability. Korean J Occup Environ Med 2008;20(4):302-313 (Korean).

38. Kjellstrom T, Kennedy P, Wallis S, Stewart A, Friberg L, Lind B, et al. Physical and mental development of children with prenatal exposure to mercury from fish: stage 2 , interviews and psychological tests at age 6. Solna, Sweden: National Swedish Environmental Protection Board; 1989, p. 1-112.

39. Choi AL, Grandjean P. Methylmercury exposure and health effects on humans. Environ Chem 2008;5:112-120.

40. Steuerwald U, Weihe P, Jørgensen PJ, Bjerve K, Brock J, Heinzow $B$, et al. Maternal seafood diet, methylmercury exposure, and neonatal neurologic function. J Pediatr 2000;136(5):599-605.

41. Food Safety Commission of Japan. Food safety risk assessment related to methylmercury in seafood; 2005 [cited 2012 Nov 8]. Available from: http://www.fsc.go.jp/english/topics/methylmercury_e1.html (Japanese).

42. United Nations Environment Programme; World Health Organization; Inter-Organization Programme for the Sound Management of Chemicals. Guidance for identifying populations at risk from mercury exposure [cited 2012 Oct 2]. Available from: http://www.who.int/foodsafety/publications/chem/ mercuryexposure.pdf.

43. Vahter M, Akesson A, Lind B, Björs U, Schütz A, Berglund M. Longitudinal study of methylmercury and inorganic mercury in blood and urine of pregnant and lactating women, as well as in umbilical cord blood. Environ Res 2000;84(2):186-194.

44. Lee KE, Hong YS, Kim DS, Han MS, Yu BC, Kim YW, et al. Mercury concentrations of maternal and umbilical cord blood in Korean pregnant women: preliminary study. Korean J Occup Environ Med 2007;19(4):268-275 (Korean)

45. Umwelt Bundes Amt. Health and environmental hygine: German Environmental Survey 1998 (GerES III); 2005 [cited 2012 Nov 8]. Available from: http://www.umweltbundesamt.de/ 
gesundheit-e/survey/us98/uprog.htm.

46. You CH, Kim BG, Jo EM, Kim GY, Yu BC, Hong MG, et al. The relationship between the fish consumption and blood total/ methyl-mercury concentration of costal area in Korea. Neuro- toxicology 2012;33(4):676-682.

47. Kim BM, Ha M, Park HS, Lee BE, Kim YJ, Hong YC, et al. The Mothers and Children's Environmental Health (MOCEH) study. Eur J Epidemiol 2009;24(9):573-583. 